\title{
COSTA RICA EN LA MIGRACIÓN REGIONAL, PERSPECTIVAS RECIENTES (2000-2014)
}

\section{COSTA RICA IN REGIONAL MIGRATION, RECENT PERSPECTIVES (2000-2014)}

\section{María José Chaves Groh*}

RESUMEN

Esta recopilación bibliográfica da cuenta del acumulado investigativo generado en Costa Rica durante el periodo 2000-2014 en torno al tema de las migraciones internacionales. Esta recopilación permite ubicar con facilidad los temas que han sido objeto de investigación en el país (considerando el doble rol de Costa Rica como escenario de origen y de destino), así como los vacíos que se han identificado en el afán de explicar la diversidad de realidades migratorias que ocurren en el país.

PALABRAS CLAVE: MIGRACIÓN * COSTA RICA * RECOPILACIÓN BIBLIOGRÁFICA * INVESTIGACIÓN

\section{ABSTRACT}

This work is a bibliographical review of all the research undertaken in Costa Rica regarding international migrations, in the period between 2000-2014. It allows easily identifying the subjects that have been studied in the country and identifying which are the areas that remain unstudied. The studies considered in this bibliographical review take into account the role of Costa Rica in international migrations, both as origin and destination country.

KEYWORDS: MIGRATION * COSTA RICA * BIBLIOGRAPHY COMPILATION * RESEARCH

Centro Centroamericano de Población (CCP), Universidad de Costa Rica.

maria.chavesgroh@ucr.ac.cr 


\section{INTRODUCCIÓN}

El presente documento consiste en una recopilación bibliográfica de investigaciones realizadas en Costa Rica en torno al tema de las migraciones internacionales a lo largo del periodo 2000-2014, las cuales han sido presentadas $y$ divulgadas en diferentes formatos (artículos científicos, libros, ponencias, informes de investigación, etc.) y por diferentes medios (publicaciones, exposiciones, Internet).

El inventario inicial incluyó 83 documentos de investigación correspondientes al período indicado, sin embargo, por razones de extensión, solo 56 de ellos se ha se han incluido en esta recopilación. Los 27 títulos restantes - relacionados con la situación de las mujeres nicaragüenses que laboran en el sector de los cuidados, los riesgos asociados a las políticas migratorias restrictivas (trata $y$ tráfico de personas), la situación de la niñez, la construcción de identidades culturales, el acceso a la justicia para las personas migrantes, el retorno, el análisis de políticas de interculturalidad y el envío y recepción de las remesasfueron ordenados y se presentan en el anexo que acompaña esta recopilación.

Por ser Costa Rica un importante destino migratorio en la región, el análisis de la inmigración ha captado el mayor interés; por lo que 34 de los 56 documentos se centran en la descripción de los perfiles de diferentes poblaciones inmigrantes, analizan la legislación migratoria y las políticas públicas, así como, las condiciones laborales $y$ de acceso a los servicios de salud. Sobre el análisis de la emigración se identificaron 13 estudios y otros 9 se enfocan en la situación de Costa Rica como escenario de inmigración y de emigración.

Este trabajo se presenta como una herramienta para quienes investigan en el campo de las migraciones, ya que además de describir el contenido de cada estudio y ubicarlo por su título, autoría; también los agrupa por escenarios migratorios (origen $y$ destino) e identifica los temas centrales de cada estudio. El documento incluye una valoración de los vacíos persistentes para explicar de forma sistemática y actualizada la diversidad de realidades migratorias que ocurren en el país.

\section{INMIGRACIÓN}

En el año 2002, la Facultad Latinoamericana de Ciencias Sociales (flacso) publicó el estudio Redes transfronterizas: Sociedad, empleo y migración realizado por Morales y Castro. Esta investigación propuso una reflexión sobre las manifestaciones de la territorialidad social producida por las migraciones entre Costa Rica y Nicaragua. Así mismo, analizó diversas dimensiones de la inmigración nicaragüense, en particular, el mercado laboral y el perfil de las personas y las familias involucradas (MoralesGamboa y Castro-Valverde 2002b).

Con estos insumos, los autores se enfocan en la conformación de un espacio transfronterizo entre ambos países "donde suceden dinámicas laborales, culturales, sociales y familiares, donde se reproduce la vida social nicaragüense $y$ costarricense, $y$ se crean $y$ recrean nuevas conductas y situaciones sociales" (Morales-Gamboa y Castro-Valverde, 2002b, p.20).

En 2007, flacso publicó, también de Morales, La Diáspora de la posguerra. Regionalismo de los migrantes y dinámicas territoriales en América Central. En esta oportunidad el autor analizó la relación entre las migraciones intrarregionales y el regionalismo en América Central, centrándose en los efectos sociales y territoriales de las migraciones de trabajadoras $y$ trabajadores en Centroamérica durante la etapa posterior a la crisis política y a los conflictos armados ocurridos entre 1990 y 2005 (Morales-Gamboa, 2007).

En 2008, el Centro Latinoamericano y Caribeño de Demografía (celade) y la Comisión Económica para América Latina (CEPAL) presentaron el estudio Inmigración en Costa Rica: características sociales y laborales, integración y politicas públicas de Morales. En esta investigación, se elaboró perfiles demográficos y laborales de la población inmigrante, se analizó su distribución geográfica, su acceso a servicios y la satisfacción de sus necesidades básicas. También, se identificó brechas en función de la edad, género, parentesco y años de residencia de las personas inmigrantes. Además, se revisó desde el enfoque de integración y de derechos, la legislación nacional y las políticas públicas 
vinculadas a la gestión de la atención a las personas migrantes.

Por último, se expuso una recopilación de las principales investigaciones sobre migración internacional realizadas en Costa Rica entre 1994 y 2006. Se concluyó con una síntesis de importantes contribuciones que las personas migrantes han hecho al país, así como, los problemas que deben enfrentar (MoralesGamboa, 2008).

En el año 2011, FLacso divulgó el estudio Migración de relevo cuyo propósito fue "estudiar los nuevos encadenamientos territoriales producidos por las migraciones intrarregionales" (Morales-Gamboa et ál., 2011, p.11). Esta investigación elaborada por Morales, Acuña, Andrade, Barrantes, Cuéllar, Herradora y Zúñiga recoge los resultados de tres estudios previos: un mapeo macrorregional de ejes de movilidad humana donde se identifican diversos flujos migratorios y sus vínculos con los mercados laborales de la región; y dos estudios de caso, uno en El Salvador y otro en Costa Rica.

En cada estudio de caso, se analizó un escenario de recepción de migrantes transfronterizos, Santa Rosa de Lima en El Salvador y Valverde Vega en Costa Rica. Estos análisis mostraron cómo interactúan simultáneamente las dinámicas migratorias de nicaragüenses $y$ hondureños que llegan a trabajar y a vivir en esos territorios; mientras salvadoreños y costarricenses emigran hacia los Estados Unidos. Por último, los autores hacen una comparación de El Salvador y Costa Rica a partir de la interrelación entre los mercados laborales y los flujos intrarregionales y extrarregionales. Para esto, consideran las expresiones territoriales de esta movilidad y su relación con los recursos naturales (Morales-Gamboa et ál., 2011).

\section{INMIGRACIÓN EN COSTA RICA: TEMAS QUE HAN SUSCITADO MAYOR INTERÉS EN LA INVESTIGACIÓN}

A partir de la literatura recopilada, se presenta una descripción de estudios que proponen diferentes análisis y enfoques para abordar la legislación y las políticas públicas en torno a las migraciones, el acceso a los derechos laborales y a los servicios de salud y la inmigración laboral de poblaciones indígenas.

ANÁLISIS DE LEGISLACIÓN Y POLÍTICAS PÚBLICAS EN TORNO A LAS MIGRACIONES

En 2006, Borge escribió el artículo Migración y politicas públicas: elementos a considerar para la administración de las migraciones entre Nicaragua y Costa Rica. Este artículo publicado por el Centro Centroamericano de Población de la Universidad de Costa Rica (cCP-UcR) destaca la importancia de contar con una política pública en materia de migración, donde el país se reconozca como receptor y como expulsor de migración. Además, propone algunos elementos para considerar en una política migratoria que regule el movimiento de personas nicaragüenses hacia Costa Rica $y$ en una política exterior de empleo pensada para costarricenses que emigran; sin embargo, el foco del análisis se centra en la dinámica Costa Rica y Nicaragua.

En esta misma línea Carmona, Chaves y Gatica (2007) publicaron en la Revista Economía y Sociedad el artículo Migración y políticas públicas: aportes para la discusión, en el cual proponen que sea el enfoque de desarrollo el que oriente las políticas migratorias. En este sentido, elaboran una conceptualización del desarrollo y analizan los aportes de la inmigración en el mercado de trabajo, salud, educación $y$ vivienda.

Posteriormente, en 2010, Jiménez publicó en la Revista Análisis Político el artículo Migración e imaginación política: Migrantes, leyes y planes de desarrollo en Costa Rica. Aquí el autor identifica diferentes movimientos migratorios que ocurren en el país. El movimiento Sur-Sur representado por personas de origen nicaragüense y colombiano que llegan a Costa Rica, movimientos Sur-Norte representado por costarricenses que migran hacia Estados Unidos, movimientos Norte-Sur representado por personas estadounidenses y europeas que vienen al país, principalmente para vivir su jubilación y por último, movimientos Sur-Sur-Norte donde personas que se mueven desde el sur de América u otros continentes hacia Estados Unidos y utilizan Costa Rica para su tránsito. 
Sin embargo, el autor señala que ha sido la inmigración nicaragüense la que ha captado mayor atención de diferentes investigaciones, en tanto la historia migratoria de ambos países se ha construido en conjunto con su modelo de desarrollo social, económico y político (Jiménez, 2010).

Un aporte importante de este estudio es el análisis de las dos últimas leyes migratorias (2005 y 2009) y el Plan Nacional de Desarrollo 2006-2010 donde el autor señala que estos instrumentos invisibilizan diversas experiencias migratorias que ocurren en el país y los aportes que brindan las personas migrantes.

Posteriormente, en 2011 Kron publicó su artículo Gestión migratoria en Norte y Centroamérica: Manifestaciones y contestaciones. La autora plantea que el rol que juega Costa Rica en el entramado migratorio de la región incide directamente en las características de las políticas migratorias y la legislación del país (Sandoval, 2005 citado en Kron, 2011).

En este artículo también se reflexiona en torno a la construcción de un espacio transfronterizo entre Costa Rica y Nicaragua, donde se desarrolla el trabajo, el comercio, los cultivos, los vínculos familiares, el acceso a servicios sociales e interactúan permanentemente diferentes actores sociales (comerciantes, migrantes en tránsito, choferes de transporte público y de carga, autoridades fronterizas, coyotes, organizaciones sociales, personas trabajadoras estacionales y permanentes, entre otros) (Kron, 2011).

También en el año 2011, el Instituto Centroamericano de Estudios Sociales y Desarrollo (IncEDes) y Sin Fronteras publicaron un Estudio Comparativo de la legislación y Políticas Migratorias en Centroamérica, México y República Dominicana. En esta investigación, se dedica un capítulo para el análisis de la situación de Costa Rica elaborado por Gatica. En este apartado titulado Estudio migratorio de Costa Rica se indica que el país ha tenido avances importantes en distintos frentes, por ejemplo reconoce constitucionalmente la igualdad entre nacionales y migrantes, promueve la integración en el marco del desarrollo, ha creado un Fondo Social Migratorio para subsidiar acciones de integración (educación, salud, seguridad, etc.) y ha incorporado a la sociedad civil en el Consejo Nacional de Migración ${ }^{1}$. Sin embargo, señala que estos avances se han concretado en el plano de la formalidad, quedando pendiente el reto de llevarlo a la cotidianidad de las personas (Gatica, 2011).

Posteriormente, en el año 2012, se defendieron tres tesis en la Facultad de Derecho de la Universidad de Costa Rica que analizaban la legislación migratoria del país, haciendo cada una énfasis en diferentes aspectos.

La tesis de Baltodano y Herrera si bien data de 2012, su análisis abarcó el periodo 2004 a 2008, cuando estuvo vigente la penúltima Ley General de Migración y Extranjería. En esta tesis, las estudiantes analizaron las implicaciones jurídicas de la falta de reglamentación de esta Ley. Ante este vacío, el Poder Ejecutivo autorizó vía Decreto Ejecutivo a la Dirección General de Migración y Extranjería (DGME) para que definiera mediante actos administrativos los requisitos para cada uno de los trámites que gestiona dicha Dirección.

Desde el punto de vista de las autoras, este procedimiento "es contrario al principio de reserva legal, por lo que adquiere un carácter ilegal y arbitrario, ya que los derechos que se le garantizan a los extranjeros en la Constitución se violentan" (Baltodano y Herrera, 2012, viII). A partir de esto, el objetivo de su trabajo, se centró en determinar el impacto de esta disposición en los derechos de las personas inmigrantes en general $y$ de las personas nicaragüenses en particular.

Otra de las tesis identificadas fue escrita por Solís-Ruballos y Guerrero-Segura, titulada Estudio crítico de la Ley General de Migración y Extranjería $N^{\circ} 8764$ en cuanto al ingreso, permanencia y egreso de los extranjeros. En esta tesis se argumenta que el enfoque de seguridad prevalece en la actual ley migratoria y que esto responde a un modelo económico que busca trabajo barato con menos garantías y derechos (desregulado).

1 Ente colegiado responsable de la definición de las políticas migratorias. 
Los autores analizan también el papel que jugaron diversos actores que participaron en la formulación de la Ley, ya que estos a su vez representaban diversas agendas; lo cual dio como resultado una ley con avances importantes, pero con serios vacíos y contradicciones que la hacen inoperante, por ejemplo, la ley dice partir de un enfoque de Derechos Humanos, pero esta misma - por los altos costos de los servicios, el exceso de trámite y de requisitoses el principal obstáculo para que las personas migrantes puedan acceder a esos derechos (Solís y Guerrero 2012).

Por último, la tesis de Salazar-Kruse titulada Las categorías de trabajador migrante a la luz de la nueva Ley General de Migración y Extranjería busca ser un insumo para armonizar la aplicación práctica de la Ley General de Migración y Extranjería ( $\mathrm{N}^{\circ}$ 8764) con el enfoque de Derechos Humanos de la persona trabajadora migrante.

En el año 2013, Salazar y Tijerino presentaron su tesis de licenciatura en derecho titulada La entrega de permisos de trabajo para trabajadores migrantes de una categoría especial y su fundamentación jurídica a la luz de la nueva Ley General de Migración y Extranjería 8764 y sus reglamentos. En este trabajo de graduación, se señala que los requerimientos $y$ lineamientos que establece la Ley $\mathrm{N}^{\circ} 8764$ son inflexibles para las personas migrantes, pero la institucionalidad, principalmente la DGME no cumple con la parte, que le corresponde (plazos de resolución, transparencia en el manejo de la información, claridad en los procedimientos) vulnerando el derecho al debido proceso. Este incumplimiento ocurre en algunos casos por dificultades administrativas y escases de personal, pero también porque el funcionariado desconoce la normativa y los procedimientos que debe seguir (Salazar y Tijerino, 2013).

Posteriormente, en 2013, Segura publica Politicas públicas y nuevas formas de acumulación en Centroamérica. En este artículo, la autora plantea que existe una estrecha interrelación entre las condiciones sociales, políticas y económicas de Nicaragua y de Costa Rica. Al respecto, señala que mientras Nicaragua se ha empobrecido $y$ ha expulsado a su población,
Costa Rica se ha enriquecido y ha dinamizado su economía con base en "los desplazados del hambre" nicaragüenses (Alvarenga, 2004 citada en Segura, 2013, p.21).

Para Segura, la actual Política Migratoria Integral y la legislación vigente se aprobaron en medio de fuertes tensiones entre organizaciones sociales $y$ autoridades de gobierno que buscaban brindar estabilidad y seguridad jurídica al sector empresarial dependiente del trabajo que desempeñan miles de inmigrantes en condición de vulnerabilidad (Segura, 2013).

Siempre en el análisis de la legislación, el Centro Feminista de Información y Acción (сеfemina) publicó en 2013, Derecho a tener derechos. Monitoreo de la aplicación de la Ley General de Migración y Extranjería ( $N^{\circ}$ 8764) y el acceso de las mujeres a un estatus migratorio regular. En este monitoreo elaborado por Chaves y Lexartza, se señala que la falta de claridad en los procedimientos que establece la Ley (principalmente, porque la DGme confunde cumplimiento de requisitos con cumplimiento de documentos que se deben entregar para las diferentes gestiones) y la falta de divulgación de dichos procedimientos, genera inseguridad jurídica a las personas que van a regularizar su condición migratoria; además, el personal de la institución no cuenta con herramientas para hacer un análisis diferenciado por condición de género para implementar la Categoría especial por razones de humanidad o para justificar técnicamente la condición de género como razón para otorgar refugio por violencia de género (Chaves, 2013). Las autoras coinciden con las tesis citadas anteriormente, al señalar que los altos costos establecidos en la Ley para los trámites migratorios son otra limitación importante para que las personas puedan regularizar su situación (Chaves, 2013).

\section{DERECHOS LABORALES}

En el año 2002, la Organización Internacional del Trabajo (огт) publicó Situación de los trabajadores migrantes en América Central elaborado por Morales. Esta investigación plantea que si bien hay un movimiento migratorio laboral histórico desde Centroamérica hacia Estados Unidos, a partir de la década del noventa, 
las migraciones internas e intrarregionales han aumentado $y$ actualmente revisten gran importancia (Morales, 2002).

Otro aspecto que destaca esta investigación es el aumento de la migración femenina con fines laborales y la notoria concentración de personas trabajadoras migrantes en actividades vinculadas a la agricultura, la prestación de servicios personales y el comercio (Morales, 2002). Además, identifica nudos que complejizan el ejercicio de los derechos laborales, perjudicando especialmente a las mujeres, a niñas, niños $y$ a personas indígenas trabajadoras.

En este contexto, la investigación señala que la institucionalidad tiene dificultades para cumplir a cabalidad con los derechos laborales de las personas migrantes, ya que desconoce sus realidades $y$ sus condiciones laborales; $y$ carece de instrumentos concretos que le permita actuar frente al incumplimiento de derechos, especialmente de trabajadoras domésticas, trabajadoras sexuales y niñez víctima de redes de trata con fines de explotación sexual y laboral.

En 2012, en el marco del proyecto "Migraciones y derechos laborales en Centroamérica: condiciones para impulsar un proceso de armonización de políticas y prácticas en el marco de la integración regional" liderado por flacso y el Instituto de Derechos Humanos de la Universidad Centroamericana (IDHucA) se publicaron tres estudios enfocados en las migraciones laborales y los derechos laborales de las personas migrantes.

En orden de publicación, el primer estudio fue del año 2012 elaborado por Segura, Estrada, Molina y Morales, titulado Migraciones y Derechos Laborales en Centroamérica: características de las personas migrantes y de los mercados de trabajo. Este estudio se llevó a cabo a partir de tres diagnósticos sociolaborales realizados uno en Guatemala, otro en El Salvador y otro en Costa Rica.

El diagnóstico de Costa Rica perfila a la población inmigrante a partir de variables sociodemográficas, país de origen, actividades laborales donde se concentran y zonas geográficas de mayor atracción. En este sentido, León et ál., destacan que la mayoría de la población inmigrante nicaragüense se encuentra en edad reproductiva, tienen menos años de escolaridad que el promedio de costarricenses y se emplean en oficios poco calificados (agricultura, construcción y trabajo doméstico) y en condiciones precarias ${ }^{2}$; además, se concentran en las zonas urbanas, sobre todo en la región Brunca y Chorotega (León et ál., 2012).

La segunda publicación, Migraciones y Derechos Laborales en Centroamérica: Elementos del marco jurídico regional formulada por Morales, León y Pérez, parte de que si bien los países centroamericanos han asumido importantes compromisos en el plano internacional en materia migratoria $y$ de derechos laborales, estos compromisos chocan de frente con legislaciones que no responden a la interrelación entre estas dinámicas. Por esa razón, analiza características sociales de las personas trabajadoras migrantes que se mueven entre los países centroamericanos y las condiciones en que les contratan. A partir de estos insumos, estudia el marco jurídico que regula los movimientos migratorios y su impacto en la protección de los derechos laborales de las personas trabajadoras migrantes (MoralesGamboa et ál., 2012).

En el año 2014, Morales, Segura, Changala y Arias realizaron una investigación que se concretó como la tercera publicación del proyecto Migraciones en Centroamérica: Estándares internacionales y capacidades estatales en materia de derechos humanos y laborales. En este estudio señala que si bien el cumplimiento de los derechos laborales en la región centroamericana tiene puntos críticos, por ejemplo en el ámbito judicial, también resulta esperanzador los esfuerzos que los ministerios de trabajo desarrollan para la inspección y la tendencia a que las direcciones de migración "tengan un enfoque más moderno y humano de los temas de las migraciones" (Morales-Gamboa et ál., 2014, p.107).

2 Diferentes estudios señalan que estas actividades es donde más se violentan los derechos laborales, las personas trabajan más horas, perciben menos salario, no tienen seguro social, vacaciones, pólizas de riesgo ni condiciones de seguridad ocupacional (MINSA 2003, p.34; León et ál., 2012, p.198). 
Otra publicación de flacso del año 2014, aunque no en el contexto del proyecto de derechos laborales, se tituló Migraciones laborales: sistematización y análisis de las politicas y los marcos de los acuerdos regionales y nacionales adoptados por los países del Sistema de Integración Centroamericana sICA (Sistema de Integración Centroamericana). En esta investigación elaborada por Changala se analiza el funcionamiento de instrumentos y mecanismos regionales que emiten políticas en materia migratoria y laboral, o bien, que representan vías para la exigibilidad de derechos, entre estos se destaca el Consejo de Ministros de Trabajo del sica, la Conferencia Interamericana de Ministros de Trabajo (сімт), los acuerdos regionales en materia de migraciones laborales y/o migraciones $y$ empleo adoptados por los países centroamericanos, los acuerdos bilaterales de cooperación entre los países de la región y las políticas públicas nacionales en materia de migraciones laborales.

Por otra parte, el Ministerio de Trabajo y Seguridad Social (мтss) concretamente la Dirección de Migraciones Laborales con apoyo de la Organización Internacional para las Migraciones (огм), orт, Agencia Española de Cooperación Internacional para el Desarrollo (AECID) y el gobierno de Canadá, ha sido un importante generador de información para conocer el mercado laboral costarricense y la inclusión o no, de personas trabajadoras migrantes.

Para el año 2008 —en pleno auge del sector constructivo- se estudió concretamente este sector. En el estudio Demanda laboral del sector construcción en Costa Rica y su componente migratorio elaborado por Araya $y$ Halsband, las autoras plantean que la incorporación de personas trabajadoras migrantes en este sector respodió a una demanda de esta actividad económica y representaba cerca del 65\% del total de trabajadores en el sector (Araya $y$ Halsband, 2008).

Posteriormente, en el año 2011 —en plena crisis económica - el мтss retoma el análisis del empleo en el sector constructivo e incluye al sector agrícola $y$ del transporte. En esta nueva investigación titulada Migrando en la crisis: la fuerza de trabajo inmigrante en la economía costarricense; construcción, agricultura y transporte público elaborada por Voorend y Robles se analizó las consecuencias de la crisis en la contratación de personas trabajadoras migrantes en las actividades económicas mencionadas. En este sentido, concluye que la construcción ha sido el sector más afectado, seguido por la agricultura; aunque en este sector el deterioro se entreteje con una crisis de varias décadas que ya venía afectándolo (Voorend y Robles-Rivera, 2011).

También en el año 2011 la огт, огм, Coordinación Educativa y Cultural Centroamericana (cEcc) del sica publicó el estudio regional Flujos migratorios intrarregionales: situación actual, retos y oportunidades en Centroamérica y República Dominicana que resultó de una investigación previa realizada individualmente en Guatemala, Belice, El Salvador, Costa Rica, Panamá, Honduras, Nicaragua y República Dominicana.

En el estudio de Costa Rica elaborado por Acuña, Alfaro y Voorend, se elaboró un perfil de la población inmigrante (aspectos sociales, demográficos, económicos y familiares), se establecieron algunas causas de la migración y se analizó el rol que juegan las remesas en la sostenibilidad de sus vínculos con familiares y con sus lugares de origen. En esta investigación, también se sistematizó información sobre el ejercicio de los derechos laborales y abordaron aspectos institucionales y jurídicos que se relacionan con la gestión migratoria en el país (Acuña et ál., 2011).

Entre sus conclusiones, se destaca que si bien en Costa Rica coexisten diferentes experiencias migratorias, la transformación en la estructura económica del país ha incidido directamente en estas dinámicas migratorias. Además, se subraya la importancia de las redes sociales (comunitarias, familiares, amistades) que facilitan la experiencia migratoria tanto en el país de origen como en la inserción en la sociedad costarricense (búsqueda de empleo, lugar donde vivir, socializar, etc.) y en la reconfiguración de los roles sociales y familiares (Acuña et ál., 2011).

Asimismo se señala —al igual que otros autores - que para las personas trabajadoras migrantes que están en condición irregular, 
no contar con un permiso de trabajo les deja en una situación de indefensión para exigir el cumplimiento de sus derechos laborales y demandar acceso a servicios de salud o a centros educativos para sus hijas e hijos. Según los autores, esta situación que se agrava frente a una institucionalidad débil que no ejerce a cabalidad su rol en la inspección y la fiscalización del cumplimiento de los derechos laborales (Acuña et ál., 2011).

Posteriormente, en el año 2013, el мтss publicó Nicaragüenses en el Norte: Condiciones laborales y prácticas de contratación de hombres y mujeres migrantes en la Región Huetar Norte. Este estudio realizado por Voorend, Robles y Venegas generó datos para caracterizar la demanda de personal migrante en la agroindustria (piña, yuca y cítricos) y el turismo (hotelería) (Voorend et ál., 2013).

En esta investigación, también se analizó la relevancia de la inmigración en Costa Rica, pero haciendo énfasis en la Región Huetar Norte y cómo esta se vincula con la estructura económica del país (Voorend et ál., 2013). Los autores presentan una caracterización de la inserción laboral de las personas migrantes (desagregada por sexo), a partir de datos de las Encuestas Nacionales de Hogares (2010-2012) y los Censos de Población (2000 y 2011), así como de las dinámicas laborales en la Región Huetar Norte sus impactos en las condiciones laborales de la población trabajadora y la segmentación por sexo. Esto con el objetivo de aportar insumos para el debate público sobre las migraciones y para el diseño de políticas públicas (Voorend et ál., 2013).

En relación con el impacto de la crisis y la contratación de migrantes, los autores concluyen que la demanda de contratación de personas migrantes en la región continuará siendo significativa e incluso, podría aumentar esporádicamente (Voorend et ál., 2013). Otra conclusión significativa es que se confirma una segmentación laboral por origen nacional que encasilla a las personas migrantes en tareas que requieren mayor esfuerzo físico y en las peores condiciones (jornada, salarios, tiempo de descanso, etc.).
Por otra parte, para el análisis de la situación laboral y migratoria, el Observatorio del Mercado Laboral (омь) de la Dirección General de Planificación del Trabajo elabora periódicamente el Anuario Estadístico. Para la presente recopilación bibliográfica, se identificaron tres Anuarios: 2010, 2012 y 2014. Estos anuarios se nutren de información brindada por las diferentes unidades del mтss que atienden público ${ }^{3}$ así como, de la Dirección de Migraciones Laborales, el Instituto Nacional de Aprendizaje (INA) $y$ el Instituto Nacional de Fomento Cooperativo (infocoop) (мтss, 2010, 2012 y 2014). Con esta información, en cada Anuario, se describe la situación general del empleo, la situación del Programa Nacional de Apoyo a la Micro y Pequeña Empresa, las relaciones obrero-patronales $y$ otra información de interés social.

Por último, el cCP-ucr en conjunto con el огм y el мтss publicaron en el año 2013 la Propuesta para la construcción de un sistema de indicadores sobre migración laboral en Costa Rica, elaborada por Barquero, González y López. Esta propuesta recoge 38 indicadores que buscan "ayudar a las instituciones $y$ entes interesados en temas de migración, a conocer y monitorear la migración laboral y su rol en los mercados locales" (Barquero et ál., 2013, p.4). En sus conclusiones, los autores identifican limitaciones y proponen recomendaciones dirigidas a las instituciones responsables de generar y suministrar la información necesaria que debiera alimentar el sistema de indicadores propuesto.

\section{DERECHO A LA SALUD}

Para el año 2003, flacso, el Ministerio de Salud (міNsa) y la Organización Panamericana de la Salud (ops) publicaron un diagnóstico

3 Dirección General de Planificación del Trabajo, Dirección Nacional de Empleo, Programa Nacional de Apoyo a la Micro y Pequeña Empresa, Dirección Nacional de Inspección, Dirección de Asuntos Laborales, Dirección de Asuntos Jurídicos, Departamento de Salarios Mínimos, Consejo de Salud Ocupacional, Dirección General de Desarrollo Social y Asignaciones Familiares, Dirección Nacional de Seguridad Social, Dirección Nacional de Pensiones, Unidad de Equidad de Género y Dirección General Administrativa. 
elaborado por Acuña, Morales, Gómez y Montiel donde caracterizan la inmigración de diferentes colectivos (nicaragüenses, colombianos, panameños e indígenas Ngäbe) que migran a Costa Rica y su situación laboral, de vivienda, educativa, demográfica y de salud (Acuña et ál., 2003).

Concretamente en el ámbito de la salud, este diagnóstico señala que persisten problemáticas vinculadas a sus condiciones de vida y de trabajo, entre las cuales destacan habitaciones insalubres, deficiente dotación de servicios básicos y malas condiciones laborales; donde la persona trabajadora se expone a maquinaria inadecuada, agroquímicos y pesticidas, así como a jornadas prolongadas, cansancio y pocas medidas de seguridad ocupacional (Acuña et ál., 2003). A partir del estudio, se señala que a estas condiciones se suma "la constante movilidad que favorece la incidencia y transmisión de enfermedades asociadas (...) principalmente en los niños, $y$ enfermedades de transmisión sexual y asociados al ambiente laboral (lumbalgias, intoxicaciones y alergias, entre otros) en los adultos" (Acuña et ál., 2003, p.34).

Posteriormente, en 2009, el Fondo de Población de Naciones Unidas (unFPa), el Centro de Derechos Sociales del Migrante (cenderos) y el Centro de Estudios y Promoción Social (cEps) publicaron el Estado de la situación de las prácticas y relaciones entre la migración y la salud sexual y reproductiva, con particular énfasis en mujeres y jóvenes de las zonas fronterizas de Costa Rica y Nicaragua. Este estudio analizó las condiciones que "determinan el ejercicio del derecho a la salud, específicamente a la salud sexual y salud reproductiva, de las poblaciones móviles y migrantes, principalmente de jóvenes y mujeres, en el territorio transfronterizo de Nicaragua y Costa Rica" (UNFPA, CEPS Y CENDERos, 2009, p.5).

Entre sus hallazgos, se destaca que la condición migratoria irregular y el temor a la discriminación y a la deportación son factores que limitan a las personas a acercarse a los servicios de salud. Coincidiendo con los estudios que abordan los derechos laborales, los autores afirman que las personas migrantes desconocen sus derechos en Costa Rica, desconocen las instituciones y los mecanismos existentes para la exigibilidad de derechos. En consecuencia, las personas se acercan a los servicios cuando su enfermedad o malestar se ha agravado y esto deteriora su calidad de vida $y$ encarece la atención médica que requieren (UNFPA, CEPS Y CENDEROS , 2009).

Concretamente en materia de salud sexual y salud reproductiva, el estudio plantea que las personas migrantes se enfrentan a los mismos problemas que las personas costarricenses (dificultades en el seguimiento de sus padecimientos, larga espera para acceder a especialistas, altas probabilidades de un embarazo no planeado, o la atención inadecuada de alguna enfermedad) (unFPA, CEPS y cENDERos, 2009). Concretamente en relación con el viH y el sida, se señala que la población móvil y migrante consultada ha tenido información $y$ aunque con algunos sesgos, conocen sobre mecanismos de transmisión y prevención (UNFPA , CEPS Y CENDEROS, 2009).

Para la atención de la salud sexual y reproductiva de las personas migrantes en este estudio se visibiliza como buenas prácticas el trabajo interinstitucional e intersectorial que se realiza en la zona, así como, las labores educativas en los puestos fronterizos, la integración de las familias a las actividades comunitarias, encuentros binacionales; $y$ la realización de Ferias de la Salud inter-fronterizas (UNFPA, CEPS Y CENDEROS, 2009).

Otro aspecto abordado en esta investigación fue la presencia de la violencia física y sexual por condición de género. Al respecto, las personas consultadas opinan que las víctimas, principalmente mujeres adolescentes y adultas, no suelen interponer denuncias porque desconocen los mecanismos que existen tanto en Costa Rica como en Nicaragua, por temor al agresor, a ser identificadas como migrantes o porque el proceso de resolución no es ágil y representa altos costos económicos (UNFPA, CEPS Y CENDERos, 2009).

Por último, en el año 2011, el Programa Conjunto de las Naciones Unidas sobre el $\mathrm{viH} / \mathrm{SIDA}^{4}$ financió el Estudio integrado de conocimientos y

4 Conformado por ACNUR, UNICEF, PIMA, PNUD, UNFPA, onUdo, oIT, Unesco, oms y Banco Mundial. 
comportamientos en relación a la salud sexual, VIH/SIDA $y$ otras ITS en la población Ngäbe y Buglé migrante, realizado por Zamora. En esta investigación, se analizó "el nivel de conocimientos y comportamientos sobre viн $y$ vulnerabilidades en la población Ngäbe Buglé para definir intervenciones futuras en el marco del acceso universal a prevención y tratamiento, cuidados $y$ apoyo" $y$ educar formadoras $y$ formadores para iniciar programas de pares que apoyaran la promoción, prevención, el acceso a pruebas y el acceso a servicios de salud en la comunidad Ngäbe Buglé tomando en cuenta su especificidad cultural y lingüística.

\section{SITUACIÓN DE LAS POBLACIONES INDÍGENAS}

En 2012, el Servicio Jesuita para Migrantes (sJM-cr) y el Servicio Jesuita para Refugiados (sJR-Panamá) publicaron En búsqueda de esperanza: migración Ngäbe a Costa Rica y su impacto en la juventud elaborado por Idiáquez. Este estudio tuvo como propósito comprender la situación de la población Ngäbe que migra periódicamente a Costa Rica para trabajar en actividades agrícolas. El autor confronta los enfoques que victimizan a estas familias y procura visibilizarles como un actor protagónico que busca de estrategias de sobrevivencia.

Este estudio también trabaja en una caracterización de la población Ngäbe y describe las condiciones en las que estas familias viven en territorio panameño, sus luchas para conservar sus territorios y su interacción con otros pueblos indígenas; esto como antesala para comprender el proceso migratorio hacia Costa Rica. Posteriormente, analiza los impactos de la inmigración en Panamá en los avances tecnológicos y económicos, para generar una discusión alrededor de las categorías de clase, raza y etnia (Idiáquez, 2012).

Más adelante, aborda la interacción entre las categorías de ciudadanía, minorías étnicas, recursos naturales, derechos humanos $y$ migración en un intento por ahondar en el ejercicio de los derechos de los pueblos indígenas en Panamá (Idiáquez, 2012). Por último, el autor se enfoca en el impacto de la migración en la cultura, la identidad y la cosmovisión de la juventud Ngäbe, contrastándolo con las visiones de las personas adultas.

En el año 2014, FLacso/ort y orm publicaron La Travesía laboral de la población Ngäbe y Buglé de Costa Rica a Panamá: características $y$ desafíos. Esta investigación realizada por Morales, Lobo y Jiménez busca comprender las dinámicas de movilidad y territorialidades de los indígenas Ngäbe y Buglé "sobre todo en su dimensión laboral; $y$ (...) explora los desafíos emergentes a partir de dicha movilidad asociadas a la inserción en mercados de trabajo agrícolas" (Morales-Gamboa et ál., 2014, p.10). Con esto, los autores reflexionan - desde el enfoque de género $y$ de interculturalidad-en torno a las políticas públicas y los mecanismos para favorecer el mejoramiento de las condiciones sociolaborales, culturales y psicosociales.

\section{EMIGRACIÓN}

A pesar de que el mayor interés de las investigaciones se ha centrado en la inmigración; también sobre la emigración de costarricenses — principalmente hacia Estados Unidos_ se ha generado vasto conocimiento.

En el periodo 2000-2014 se identifican 13 estudios, entre los cuales se ubican artículos, tesis, libros e informes de investigación divulgados públicamente.

En el año 2007, se presentaron dos trabajos finales de graduación vinculados a la emigración de costarricenses. La primera es una tesis para optar al grado de Licenciatura en Economía elaborada por Leiva titulada Caracterización Socioeconómica de la Población Emigrante de Pérez Zeledón, período 1991-2006. Esta tesis expone una caracterización de la migración costarricense en el contexto centroamericano e internacional, y centra su análisis en las remesas (concepto, clasificación, mecanismos de envío, contribución al desarrollo). El autor expone una caracterización socioeconómica de la región Brunca y del cantón de Pérez Zeledón, analizando los impactos socioeconómicos de la emigración y el uso de las remesas en ese cantón.

La segunda tesis realizada por Barrientos se titula Sueño norteamericano: imán atrayente: Un estudio de caso sobre los efectos 
de la reinserción del o la emigrante en Pérez Zeledón y lo conocido popularmente como la Zona de Los Santos, realizada para optar por el grado de Licenciatura en Trabajo Social. Este estudio tiene como propósito analizar la reinserción familiar de hombres y mujeres de la zona de Los Santos y Pérez Zeledón que emigraron. Para esto, la investigadora utiliza el enfoque de género para comprender la vivencia personal $y$ familiar (mujeres/rol de madres $y$ los hombres/rol de padres) de la migración (antes y durante) y la reinserción familiar al retorno.

En el año 2008, la organización Alianza por tus Derechos sistematizó los resultados del proyecto La Voz de los Niños, Niñas y Adolescentes del cantón de Pérez Zeledón sobre la migración. Esta sistematización recoge las reflexiones de personas menores de edad, madres $y$ docentes de primaria $y$ secundaria sobre lo que piensan de la migración, el impacto de las remesas en sus vidas y la percepción de niñas, niños y adolescentes sobre la migración de su papá o su mamá.

También en el año 2008, Monge defendió la tesis Buscando el Paraíso Americano: Una mirada geográfica de la migración desde los sectores cafetaleros de Pérez Zeledón, Costa Rica hacia Estados Unidos (1984-2006). Este trabajo final de graduación aplicó el método geográfico del análisis de campo a partir de los datos de 391 emigrantes de Rivas/San Isidro; Cajón/San Pedro y Platanares/Pejibaye del cantón de Pérez Zeledón. Con estos datos caracterizó las experiencias migratorias de estas personas (hombres en su mayoría) considerando su ruta migratoria, su ocupación antes de migrar, su ocupación en Estados Unidos, sus motivos para migrar y la inserción en redes sociales para concretar la migración. Otro aspecto relevante es la identificación de algunos elementos que apuntan hacia la conformación de espacios transnacionales y analiza el impacto de las remesas en los cambios de uso de suelo en la zona y en el bienestar de las familias que quedan en las comunidades de origen.

En el año 2010, Caamaño publica el libro Entre "arriba" y "abajo". La experiencia transnacional de la migración de costarricenses hacia Estados Unidos. Este libro es resultado de su tesis doctoral sobre la construcción de espacios transnacionales formados por emigrantes, emigrantes de retorno, sus familiares y las comunidades en Los Santos y Pérez Zeledón (Costa Rica) y Bound Brook, New Jersey (Estados Unidos) (Caamaño-Morúa, 2010).

En su estudio, la autora analiza cómo se organiza la reproducción social de la fuerza de trabajo en Estados Unidos y en Costa Rica, y entre ambos países en un contexto de restructuración del capitalismo global. Aborda también las prácticas de consumo y su incidencia en procesos de construcción identitaria como evidencia de la conformación de comunidades transnacionales (Caamaño-Morúa, 2010). Reflexiona también sobre:

Los procesos de control, gubernamentalidad, resistencia, acomodación y negociación de las y los sujetos en el espacio transnacional, a través de los procesos de inserción laboral, reproducción social, y construcción de subjetividades, a partir de la clase social, el género, la etnia y la nacionalidad (Caamaño-Morúa, 2010, p.xxII).

En torno a la publicación de este libro se identificaron cuatro artículos científicos publicados: 1) Espacio trasnacional e identidad de los Ticos Entre "Arriba" y "Abajo" (2007), 2) La ambigüedad como salud mental: la construcción de identidades nacionales entre migrantes transnacionales costarricenses (2010), 3) Procesos de acumulación, migración transnacional y subjetividad en Los Santos, Costa Rica: una perspectiva de investigación desde la economía politica cultural crítica (2012) y 4) Espacios de gubernamentalidad entre el "centro" y la "periferia": definiendo la migración y el desarrollo de la zona de Los Santos (2012).

En el año 2011, la ops/oms publicó Migración de enfermeras de América Latina. Área de América Central, México y el Caribe Latino realizado por Cabrera. Aunque el estudio es regional, dedica un capítulo a Costa Rica, donde caracteriza la migración de enfermeras a partir de la magnitud, razones y propósitos de la migración. Además, analiza normas y tratados vinculados a la migración, aspectos económicos 
$y$ posibles consecuencias de esta migración en los servicios de salud costarricenses.

Este estudio se complementó con otro publicado por ops en el año 2013 titulado Panorama de la Migración de médicos y enfermeras de la región de Centroamérica y República Dominicana. Esta investigación generó insumos que podrían utilizarse para la construcción de políticas y estrategias para la gestión de la migración del personal de salud en la región. Para esto se sistematizó - por país - información relacionada con la certificación de la formación y el ejercicio profesional, así como, la habilitación de profesionales; además, analizó la percepción que tienen autoridades de Recursos Humanos de las instituciones con relación al proceso migratorio, su impacto en los servicios de salud y posibles alternativas para minimizar esos impactos.

Por último, recopiló información de cada país para evaluar la magnitud y temporalidad de la migración de médicos y enfermeras.

En el año 2012, unesco impulsó a nivel regional una serie de investigaciones en torno al tema migratorio. Para el caso de Costa Rica este estudio realizado por Chaves se tituló ¿Quiénes se fueron y quiénes se quedan?: Retratos de la emigración costarricense y su objetivo fue visibilizar el acumulado investigativo que el país desarrolló en el periodo 2007-2011 sobre la emigración de costarricenses. Además, la autora identificó avances en el accionar del Estado e hizo recomendaciones para mejorar la protección de los derechos de las personas migrantes costarricenses.

También en el año 2012 en el marco del "Programa de aplicación de los principios generales para los mercados de remesas de América Latina y el Caribe" Cervantes realizó El perfil de la población de origen costarricense en Estados Unidos a partir de datos censales de Estados Unidos de 2000 y 2010, de la Encuesta de la Comunidad Estadounidense (2011) e información del Departamento de Seguridad Nacional de Estados Unidos y del Banco Mundial. Este estudio buscaba ser un insumo para que autoridades en Costa Rica se acerquen a la población emigrante, además de mejorar las condiciones de envío, recepción, costos y la gestión de las remesas que envían a Costa Rica.

\section{ESTUDIOS SOBRE LA INMIGRACIÓN Y LA EMIGRACIÓN EN COSTA RICA}

Además de investigaciones que se centran en la inmigración o la emigración, se identificaron 9 estudios que abordan ambas dinámicas.

En el año 2003, Barquero y Vargas publicaron La migración internacional en Costa Rica: Estado actual y consecuencias. Este artículo caracterizó la migración en el país a partir de los resultados del ix Censo Nacional de Población realizado en el año 2000. Este artículo fue de particular importancia ya que desde 1984 el país no contaba con información censal, por lo que este Censo generó gran expectativa desde la institucionalidad y la academia para conseguir dimensionar y caracterizar los cambios migratorios que el país estaba enfrentando, así como, su impacto en la estructura sociodemográfica y económica.

En sus hallazgos, los autores constatan el aumento de la inmigración — principalmente de origen nicaragüense - en la última década. Con relación a la emigración costarricense, confirman que el principal destino es Estados Unidos, también en este escenario identifican un aumento considerable pasando de 45000 personas en el año de 1990 a casi 70000 en el año 2000, según censos de ese país (Barquero y Vargas, 2003).

En el año 2007, Carlos Sandoval publicó el libro El Mito Roto: Inmigración y emigración en Costa Rica. Este texto refleja experiencias migratorias que ocurren en Costa Rica en al menos tres corredores: Sur-Sur representado por personas nicaragüenses y colombianas que llegan al país, Sur-Norte representado por costarricenses que migran hacia Estados Unidos y movimientos Norte-Sur. En este libro, el editor reúne 19 artículos organizados en cinco secciones:

1) Comunidades migrantes en Costa Rica: recoge cinco artículos que exploran el origen y situación de las principales comunidades inmigrantes en Costa Rica, a partir de fuentes históricas de información 
censal y del análisis contextual particular (Barquero, 2007-2008).

2) Inmigración y políticas públicas: incluye dos artículos que abordan los impactos de la inmigración nicaragüense en los servicios públicos de Costa Rica, particularmente en el servicio de salud y seguridad social (Barquero, 2007-2008).

3) Emigración costarricense: incluye un artículo sobre las remesas que envían los emigrantes costarricenses desde el exterior, así como, las condiciones históricas y socioculturales actuales en zonas específicas de origen $y$ destino de estos emigrantes ticos (Barquero, 2007-2008).

4) Inmigración y género: reúne cuatro artículos que analizan la migración laboral transfronteriza, la salud reproductiva, las condiciones laborales en la agroindustria de exportación y el turismo sexual a partir del enfoque de género.

5) Imaginarios sociales de la migración: incluye dos artículos que analizan el chiste como mecanismo de reproducción de las condiciones en que las y los costarricenses conviven con el "otro" $y$ la "otra" migrantes, frente a la mirada del poder y la violencia simbólica de un "nosotros" mayoritario. Un tercer artículo sistematiza la experiencia de documentar en video las imágenes cotidianas del nicaragüense en Costa Rica.

El libro cierra con un artículo del editor donde reflexiona en torno a una agenda para continuar y profundizar la investigación y la acción en materia de migraciones (Barquero, 2007-2008). En el contexto de la presentación del texto editado por Sandoval, Barquero publica un artículo-presentación del libro, en el cual recoge una serie de mitos que persisten en el imaginario social y que contrasta con los hallazgos de los diferentes artículos del libro.

En el año 2009, Jiménez publica su libro La vida en otra parte. Este texto analiza cómo inmigrantes y emigrantes participan en la construcción de los patrones y las prácticas culturales costarricenses, recuperando también las tensiones derivadas de esa participación.
El autor plantea las tensiones que se presentan entre personas migrantes $y$ refugiadas $y$ personas costarricenses expresadas en la desconfianza, el temor, la hostilidad y la exclusión.

Por otra parte, en la administración 2010-2014, la DGme creó internamente la Dirección de Integración y Desarrollo Humano. Esta nueva Dirección publicó en 2011, su primer Informe de Integración y Migración y en el año 2012, publicó el segundo de estos. Ambos informes recopilan información de diferentes instituciones para dar cuenta de la integración social de las personas migrantes al país.

El Informe 2011 por tratarse del primero buscaba establecer una línea base referencial para organizar y priorizar actividades estratégicas en materia de integración social.

Si bien, el Informe 2012 mantiene una estructura similar al Informe anterior, los autores agregan apartados importantes con relación a la emigración costarricense. En este sentido incorporan estimaciones de los movimientos migratorios a partir de datos de la DGME para identificar ingresos y egresos del país, asî como, el otorgamiento de documentos migratorios (pasaportes a costarricenses o documentos de identificación a personas migrantes), caracteriza la emigración costarricense a partir de datos del x Censo de Población 2011 y datos de los estudios de remesas del Banco Central de Costa Rica. Además, analiza la salida y entrada de remesas y reflexiona en torno a la percepción de la población costarricense con relación a la inmigración y la emigración.

En el año 2013, la Universidad Estatal a Distancia (uned) en convenio con la orm publicó el Diagnóstico Socioeconómico y de Oportunidades de mercado para la población migrante de la Subregión de Los Santos. Esta investigación realizada por Mondol y Amador sistematiza la situación socioeconómica de la población nacional migrante retornada y de familiares, así como de la población inmigrante panameña Ngäbe-Buglé de la subregión de Los Santos. Posteriormente, los autores analizan la dinámica económica y los principales problemas 
socioeconómicos que enfrentan las diferentes poblaciones que conviven ahí (Mondol y Amador, 2013).

Para finalizar, presentan un inventario de recursos económicos de Los Santos para distinguir las limitaciones y potencialidades de la subregión, así como de las principales oportunidades de mercado (Mondol y Amador, 2013).

En el año 2013, el ccP-ucr difunde su Evaluación demográfica del $x$ Censo Nacional de Población de Costa Rica 2011 y de otras fuentes de información. Esta evaluación se llevó a cabo en el marco de un convenio suscrito con el Instituto Nacional de Estadística y Censo (INEC) que data desde el año 2002. Para efectos de esta recopilación bibliográfica es de particular interés la evaluación del saldo migratorio donde se contrasta la información censal con información suministrada por la DGME.

En el año 2014, el Ministerio de Gobernación y Policía publica el Informe Migración y Desarrollo en Costa Rica. Este Informe busca profundizar algunos aspectos donde se encuentran la migración y el desarrollo, discutidos en el Primer Diálogo Nacional sobre Migraciones y Desarrollo realizado en agosto de 2013, de cara al Diálogo de Alto Nivel sobre Migración Internacional y Desarrollo, convocado por la Asamblea General de la Organización de las Naciones Unidas.

En este contexto, el Informe describe $y$ analiza las principales dimensiones de la migración, el desarrollo y el desarrollo humano; e identifica avances, desafíos y propuestas para que el país gestione las migraciones desde la perspectiva del desarrollo y los derechos humanos (Ministerio de Gobernación y Policía, 2014).

\section{CONCLUSIONES}

Las migraciones en Mesoamérica son sumamente dinámicas y Costa Rica no es ajena a esas transformaciones constantes. Esto representa un desafío permanente para la investigación desde las diferentes disciplinas de las ciencias sociales, ya que cuando se consigue profundizar en determinada línea, los escenarios se modifican y los actores sociales cambian, las recomendaciones se desactualizan y se generan nuevos vacíos.
A continuación se identifican algunos temas pendientes de explorar para releer las realidades migratorias que ocurren actualmente en el país.

$\diamond \quad$ Esta recopilación bibliográfica constata que aunque la literatura identifica diferentes dinámicas migratorias que ocurren en el país (Sur-Sur, Sur-Norte, Norte-Sur y Sur-Sur-Norte), el bagaje investigativo se enfoca principalmente en el análisis de las migraciones intrarregionales, concretamente en el corredor migratorio Nicaragua-Costa Rica y en menor medida la migración temporal indígena Ngäbe. En consecuencia se ha generado poca o ninguna literatura sobre la migración de tránsito o la inmigración de colectivos de otros orígenes nacionales, por ejemplo, estadounidense, europeo o desde otros países de América Latina.

$\diamond \quad$ También es necesario generar análisis sobre las condiciones de retorno e integración de costarricenses que regresan al país, tanto de forma voluntaria como no voluntaria.

$\diamond \quad$ Es necesario conocer las condiciones de integración para los diferentes colectivos de inmigrantes que residen en el país, tanto de primera como de segunda generación. Ahondar en las condiciones específicas por poblaciones: mujeres, niñas y niños, hombres, personas adultas mayores.

$\diamond \quad$ Cuantificar el peso de la participación de la población migrante en la economía nacional $y$ en sus diferentes sectores.

$\diamond \quad$ Caracterizar el perfil educativo de las personas inmigrantes (no solo nicaragüenses) y emigrantes, así como, las ocupaciones en que se desempeñan para determinar si la experiencia migratoria mejora o desmejora su cualificación y el impacto que esto tiene en el país.

Fecha de ingreso:12/12/2016 Fecha de aprobación: 19/05/2017 


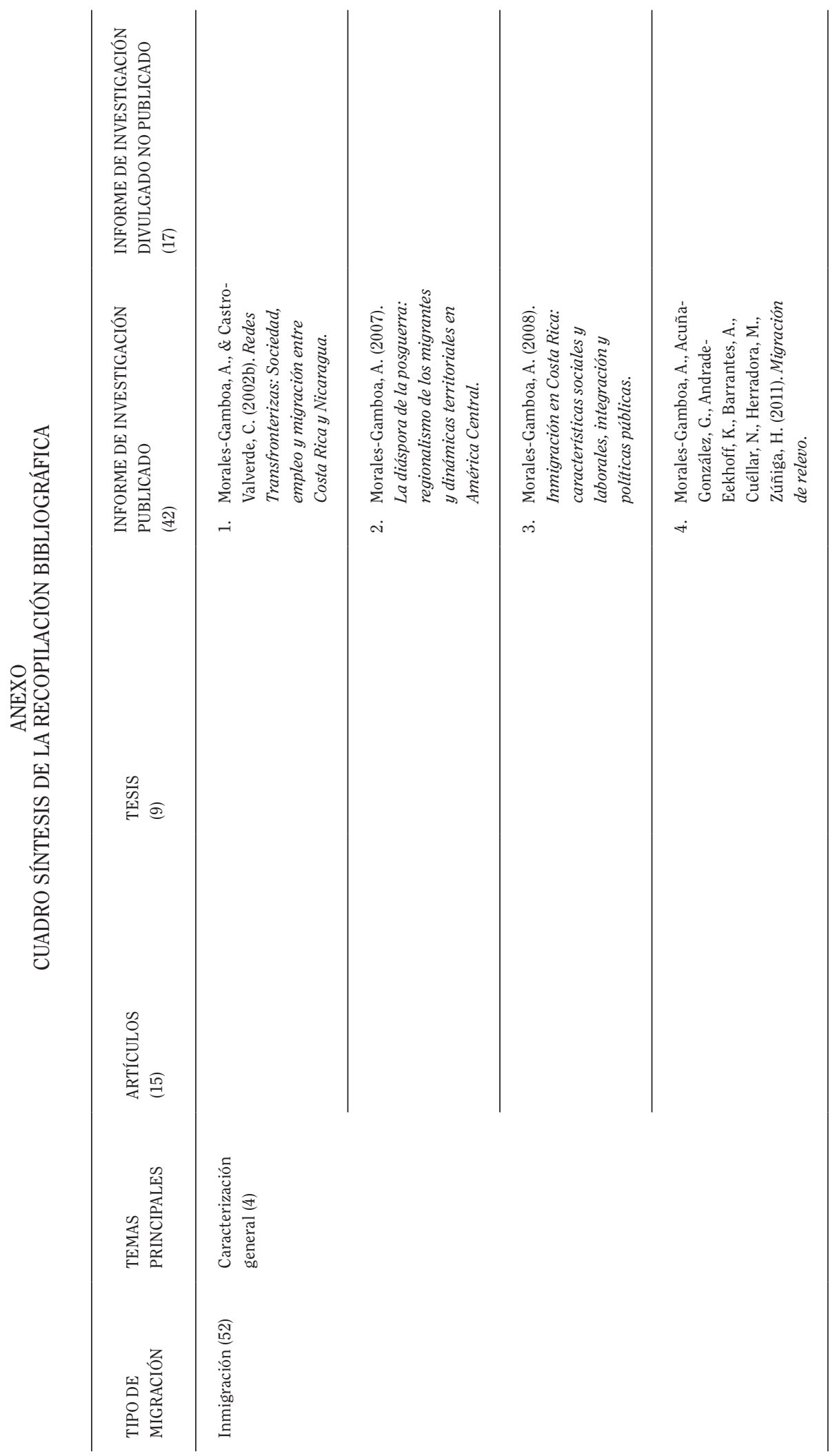




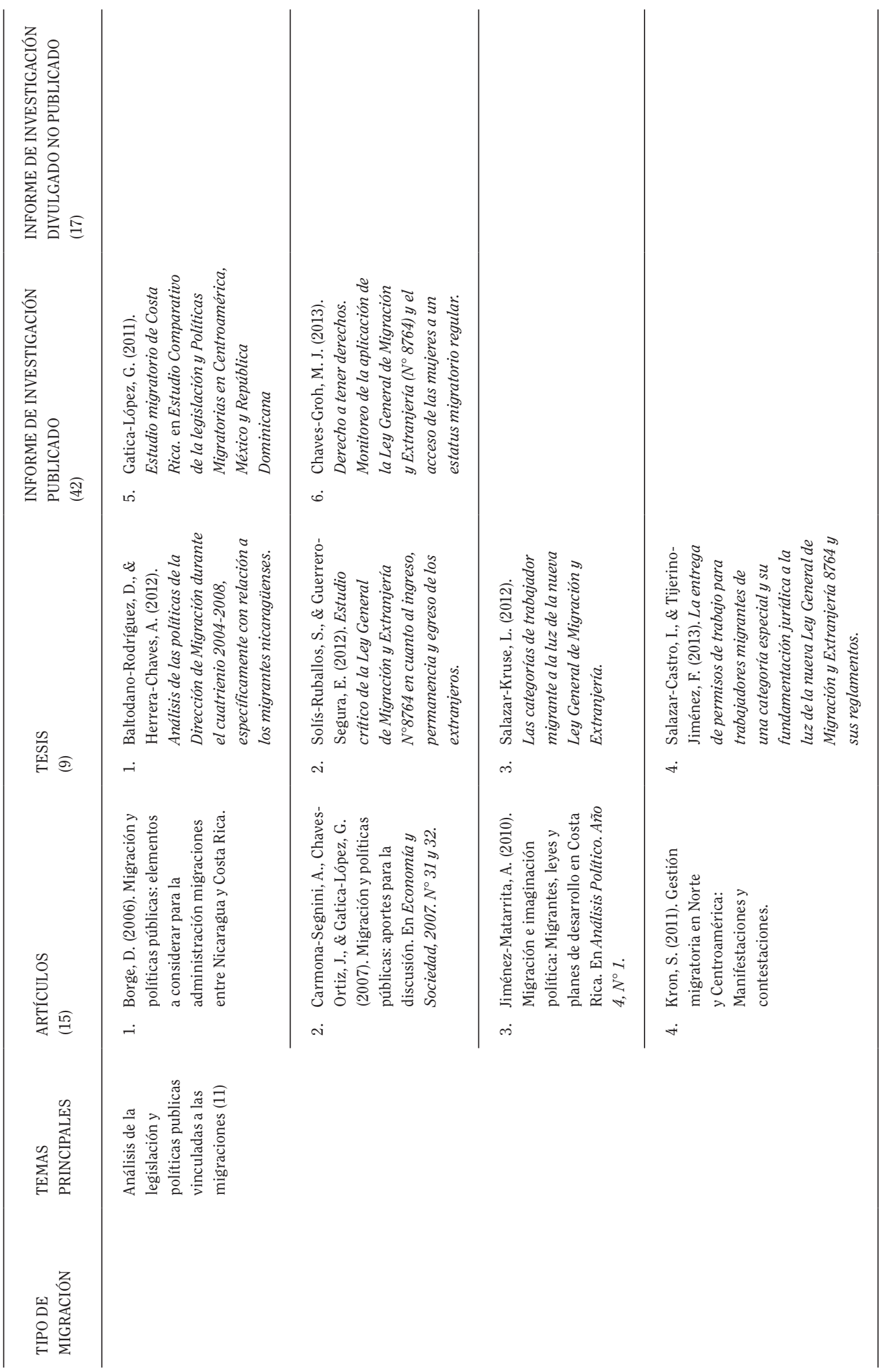

(c) (1) (ㄷ) Rev. Ciencias Sociales Universidad de Costa Rica, 157: 27-52 / 2017 (III). (ISSN: 0482-5276) 


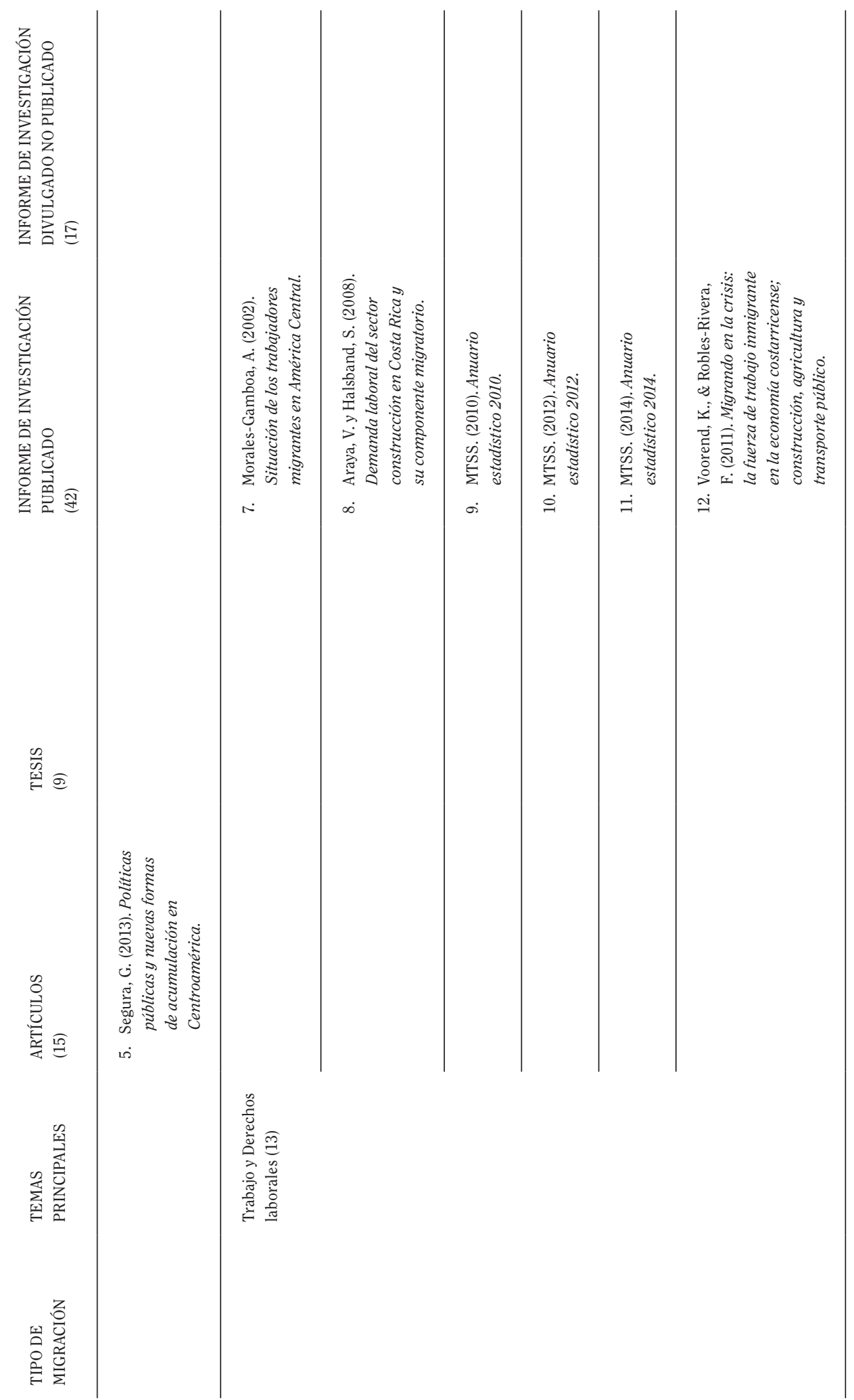




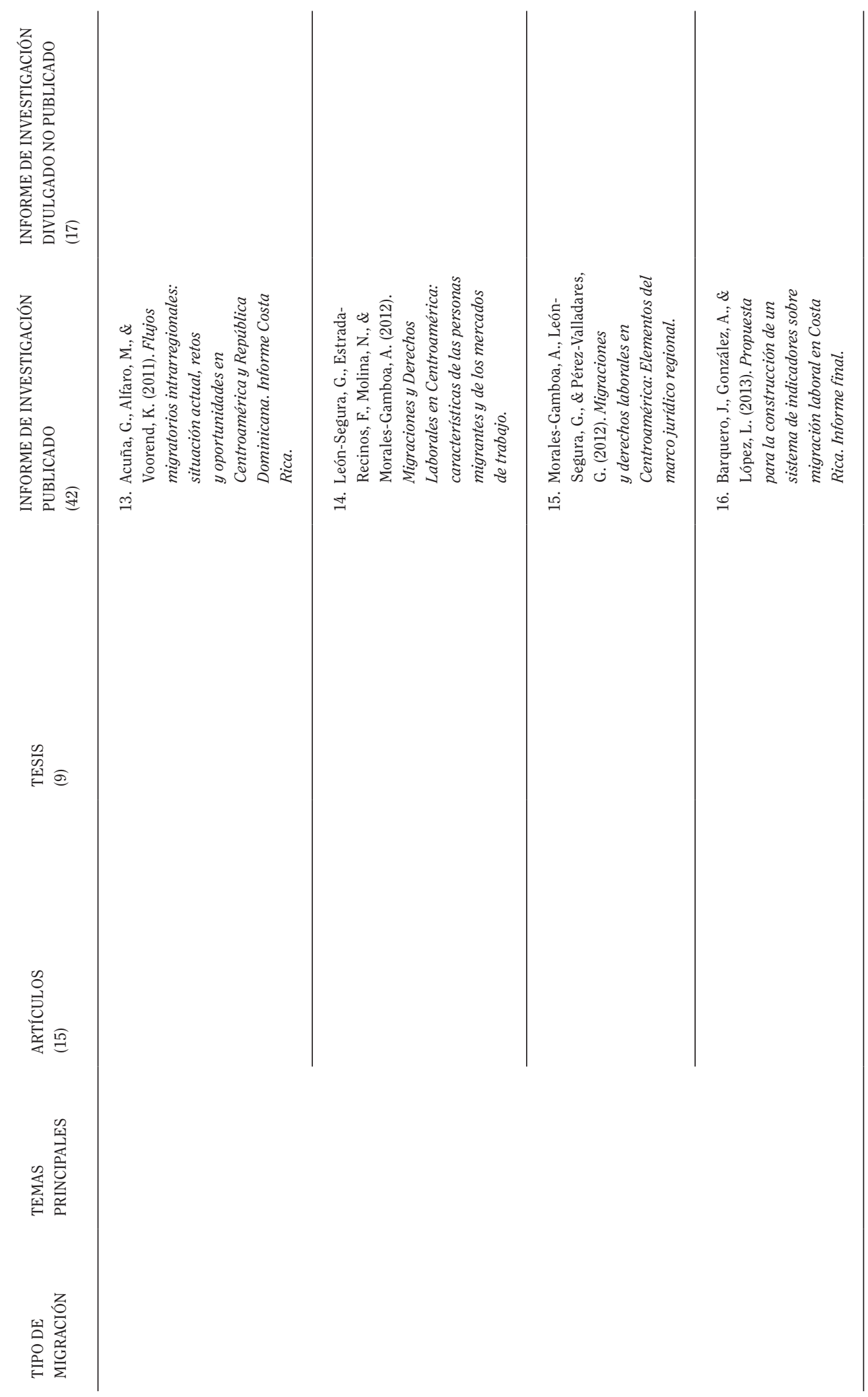




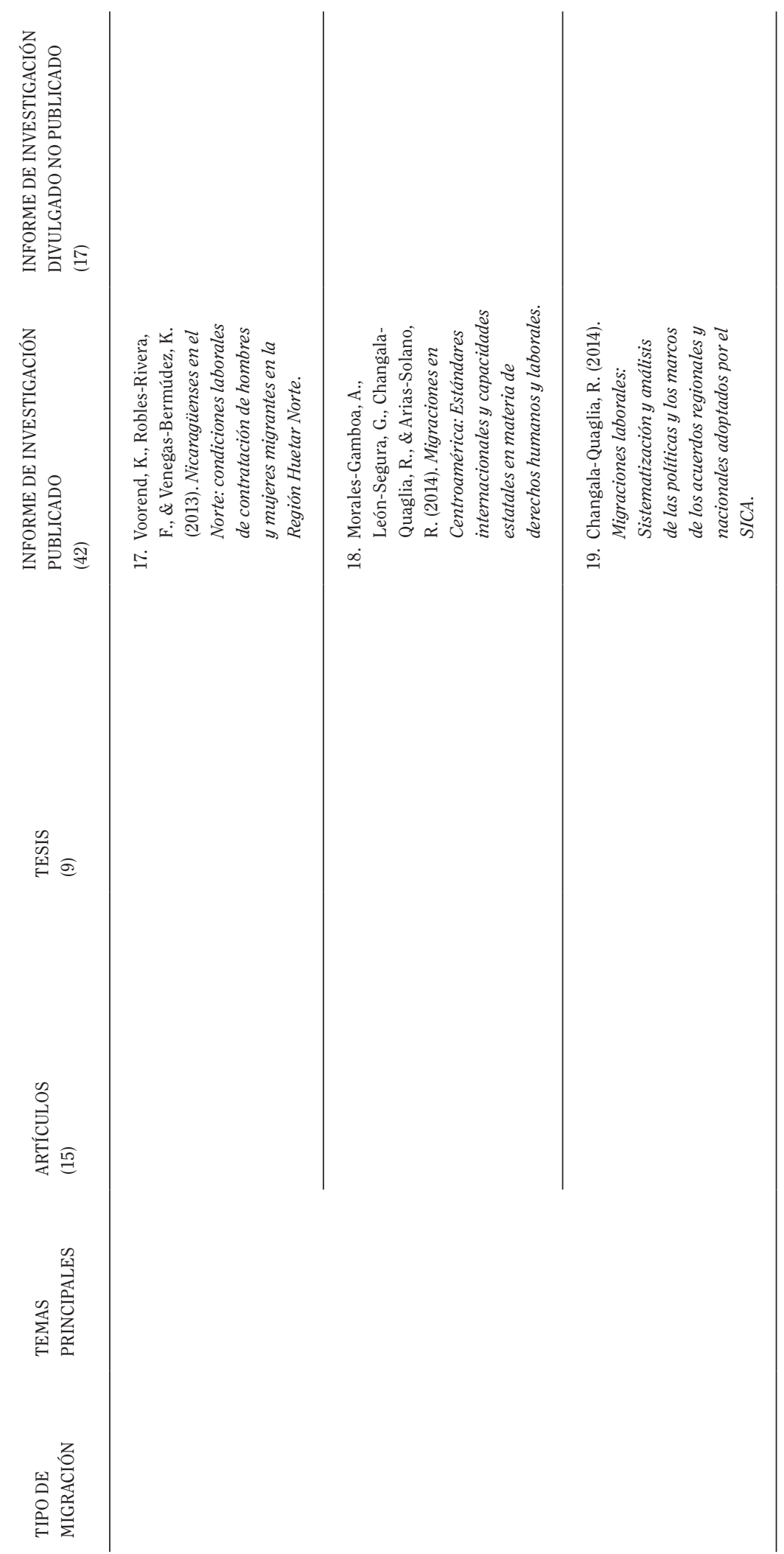




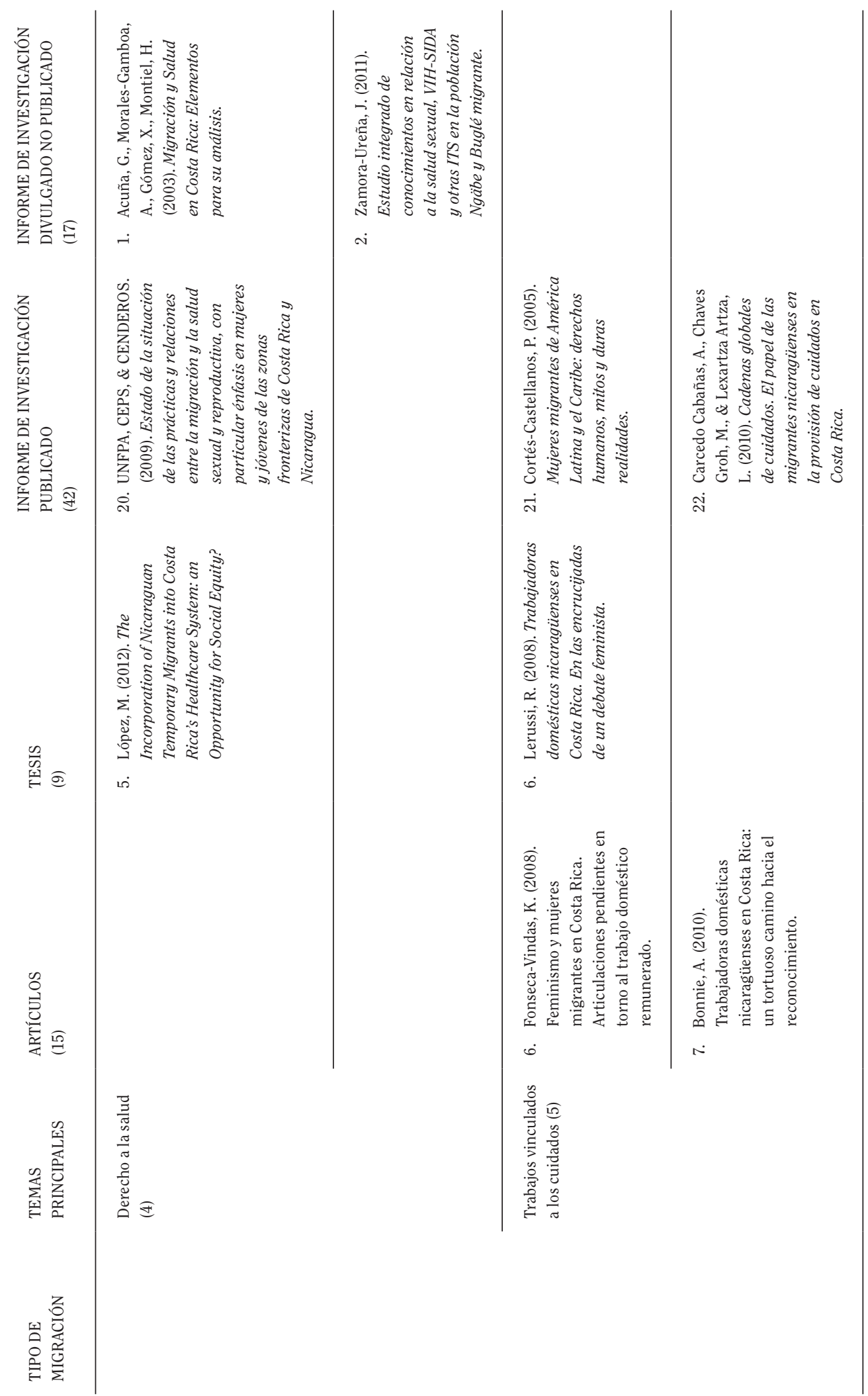

(c) (1) (ㄷ) $\Theta$ Rev. Ciencias Sociales Universidad de Costa Rica, 157: 27-52 / 2017 (III). (ISSN: 0482-5276) 


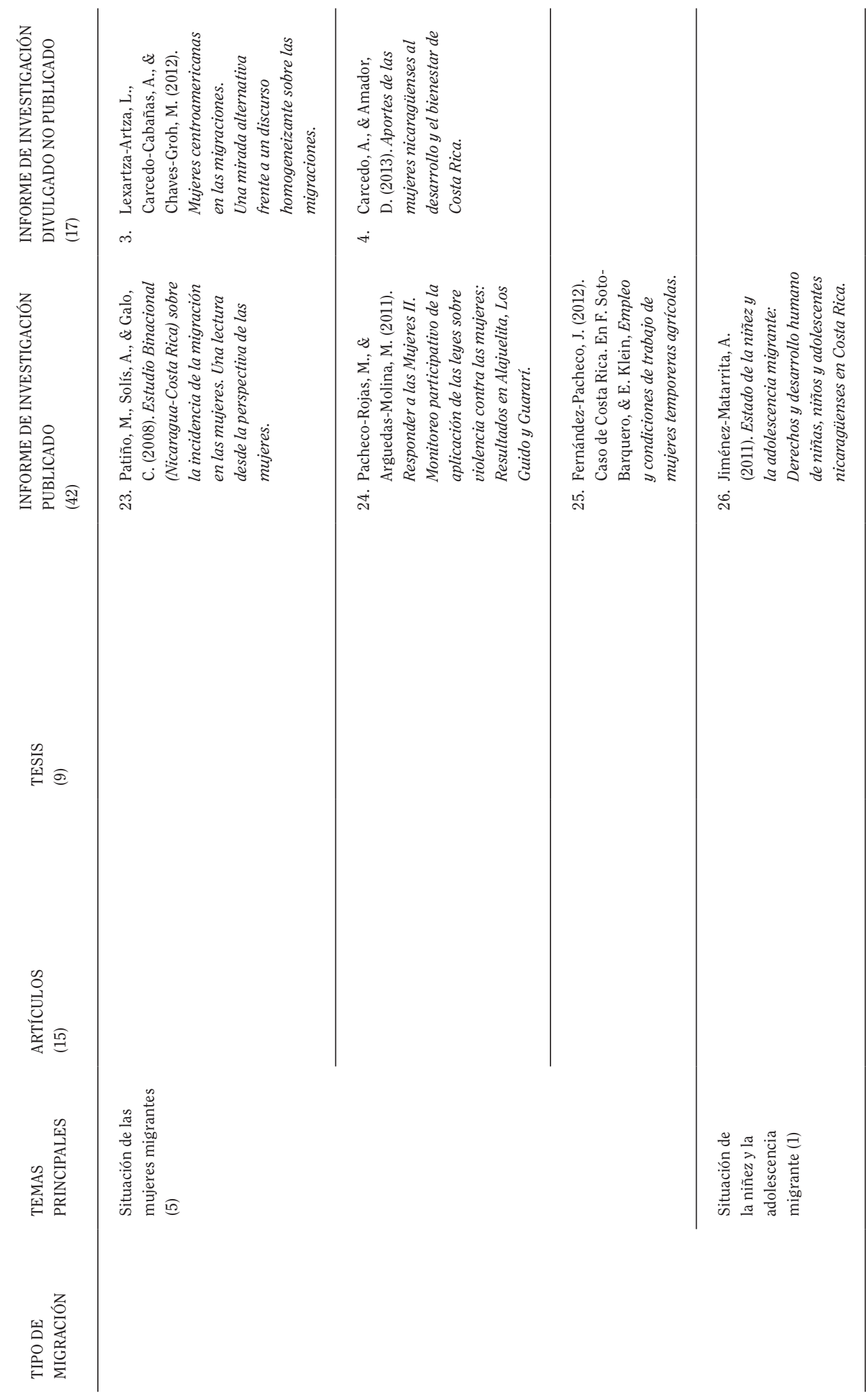




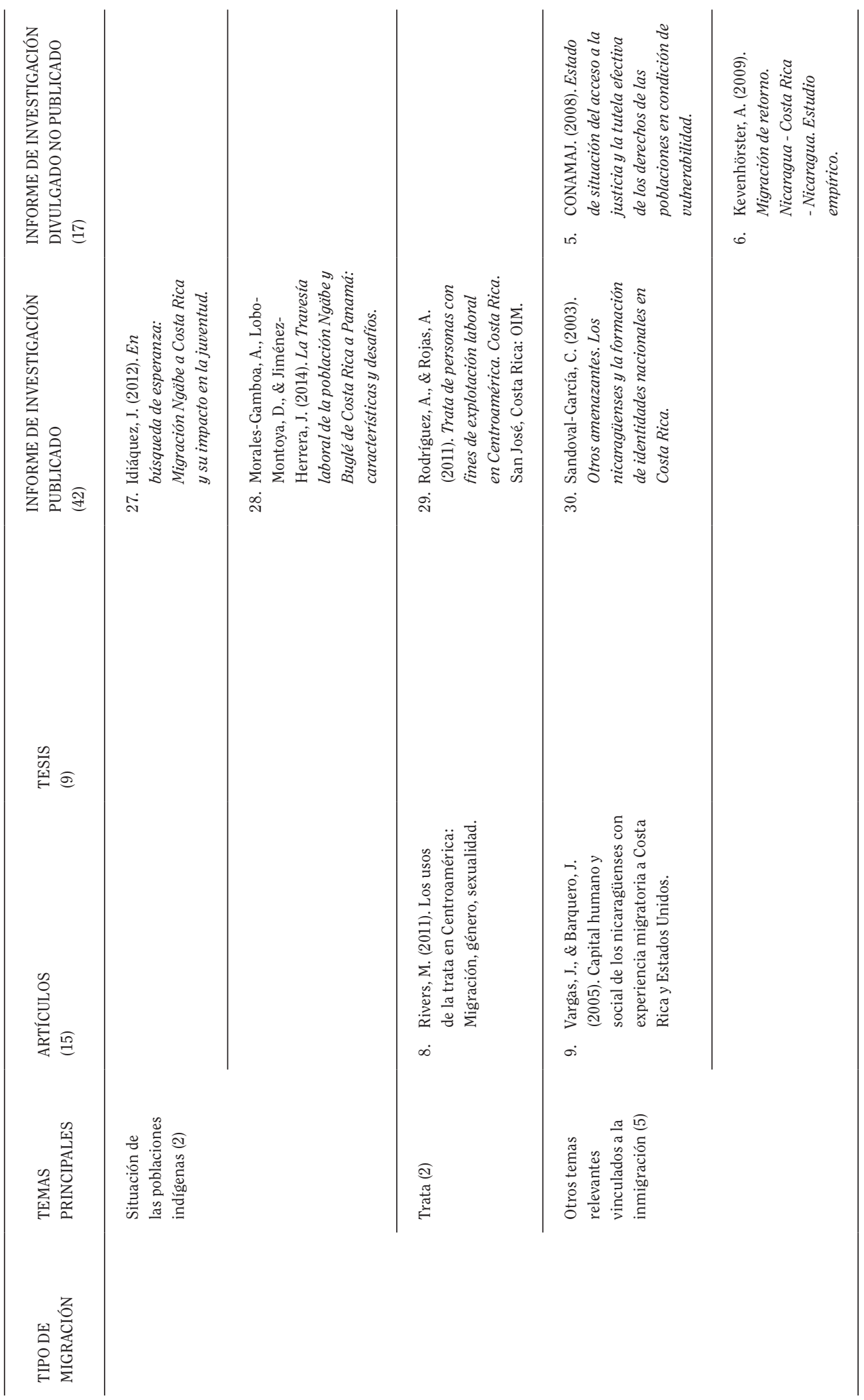

(c) (i) $($ Rev. Ciencias Sociales Universidad de Costa Rica, 157: 27-52 / 2017 (III). (ISSN: 0482-5276) 


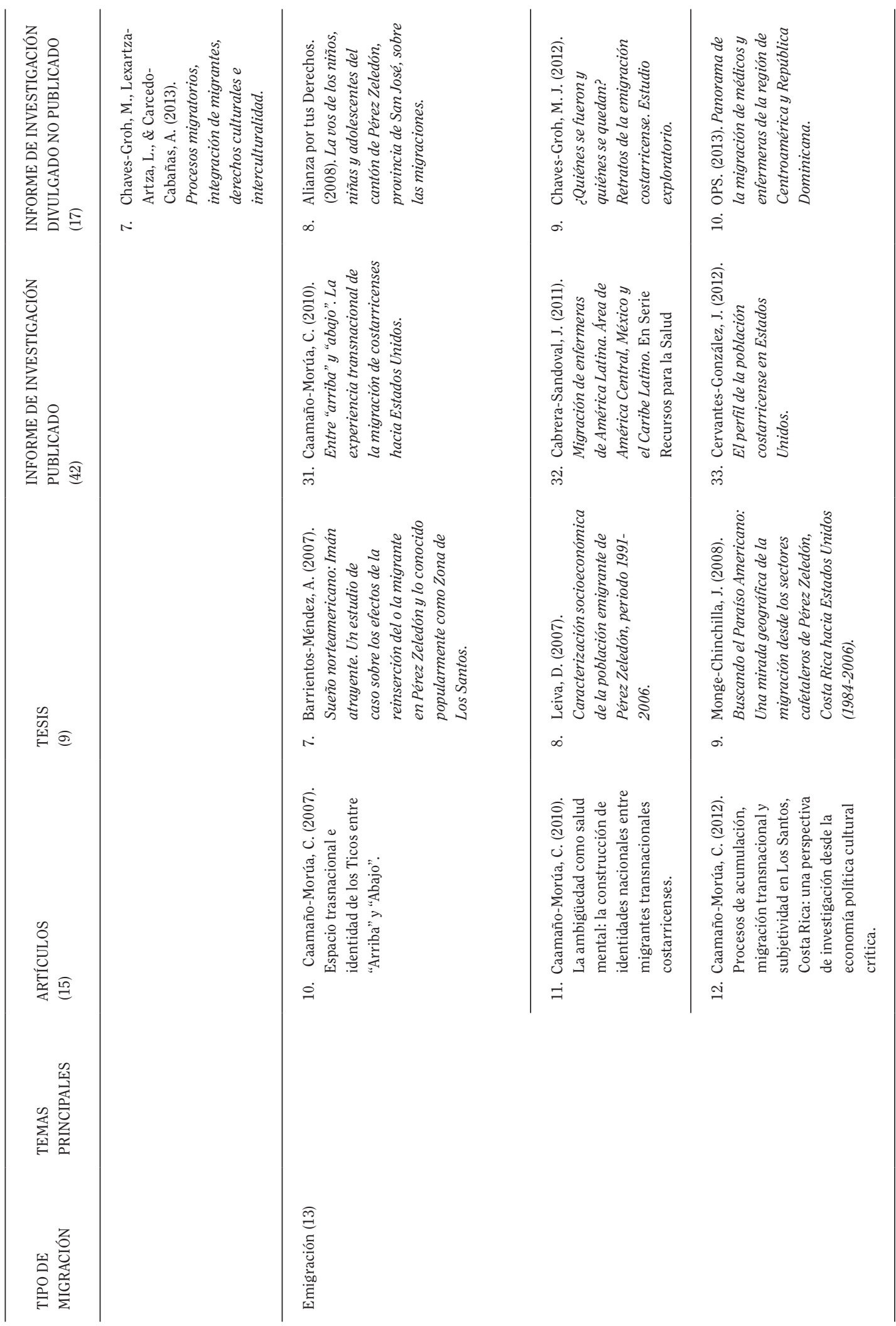




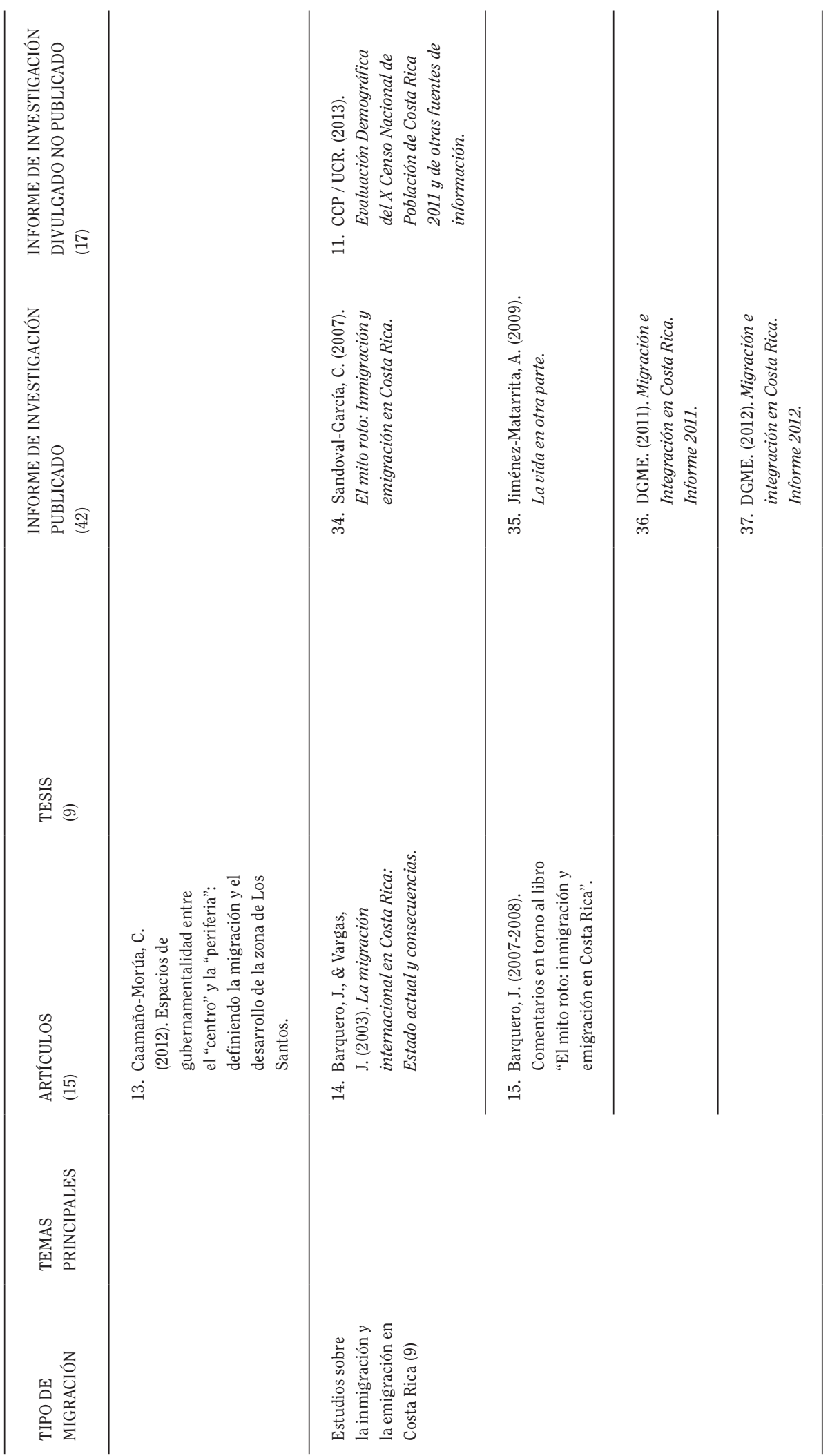

(c) (1) (ㄷ) $\Theta$ Rev. Ciencias Sociales Universidad de Costa Rica, 157: 27-52 / 2017 (III). (ISSN: 0482-5276) 


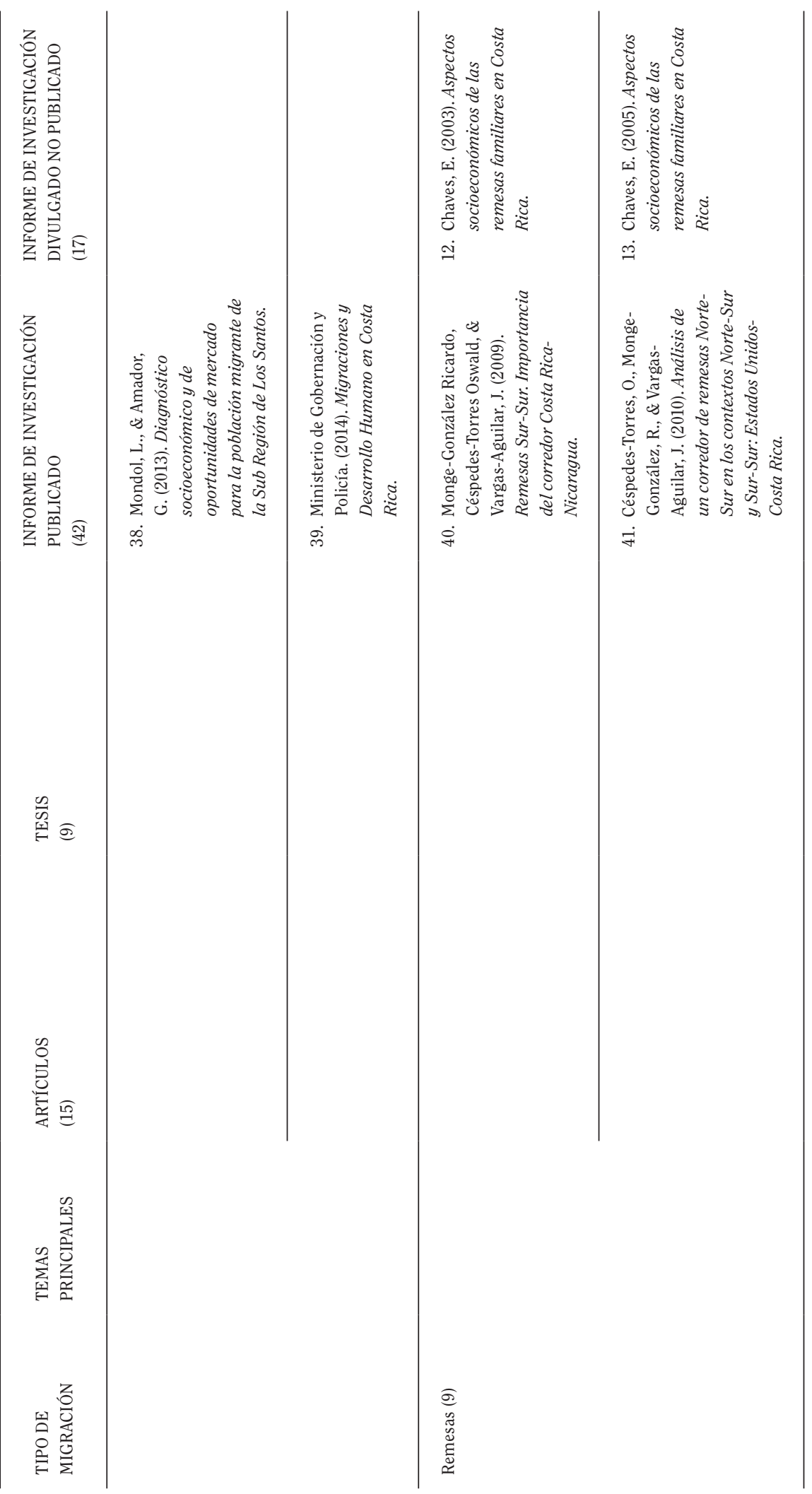




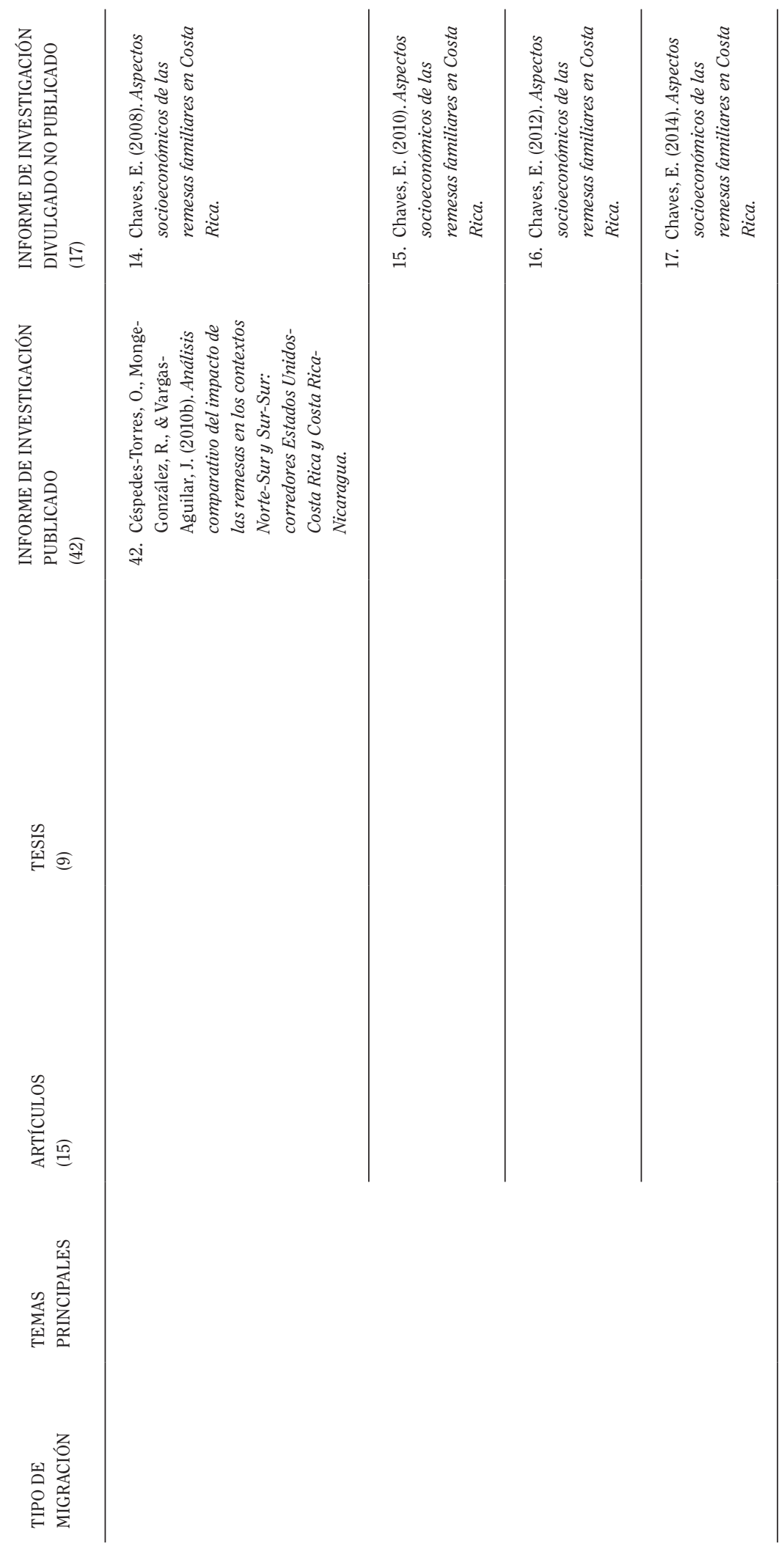

(c) (1) (ㄷ) $\Theta$ Rev. Ciencias Sociales Universidad de Costa Rica, 157: 27-52 / 2017 (III). (ISSN: 0482-5276) 